\title{
Convenient Synthesis of 3-Amino-2-hydroxy-5-methylbenzenesulfonic Acid
}

\author{
V. M. Ismailov，F. N. Nagiev, and N. N. Yusubov \\ Baku State University, ul. Z. Khalilova 23, Baku, AZ-1148, Azerbaijan \\ e-mail:niftali-yusubov@rambler.ru
}

Received August 28, 2012

DOI: $10.1134 / \mathrm{S} 1070428013060249$

Amino-substituted benzenesulfonic acids are important building blocks for the synthesis of pharmacologically active derivatives of sulfanilic acid. 4-Aminobenzenesulfonic acids are commonly prepared by sulfonation of aniline with sulfuric acid. This procedure is applicable to the synthesis of 4- and 2-aminobenzenesulfoinic acids.

We have found a new method for the preparation of 3 -aminobenzenesulfonic acid derivative via reaction of 2-hydroxy-5-methylphenyl methyl ketone oxime with excess sulfuric acid. By heating that oxime and $60 \%$ sulfuric acid in an inert solvent over a period of $2 \mathrm{~h}$ we obtained 3-amino-2-hydroxy-5-methylbenzenesulfonic acid (I) (Scheme 1).

Scheme 1.

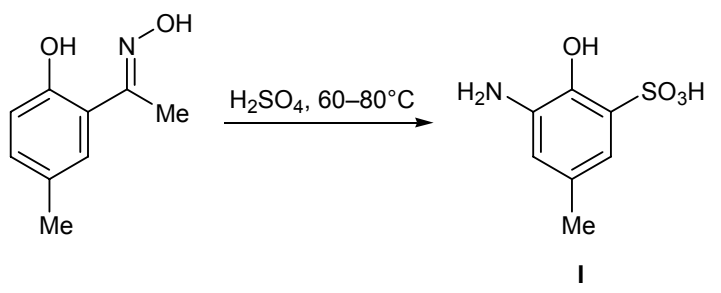

The reaction is likely to involve Beckmann rearrangement of the initial oxime with formation of the corresponding acetanilide which undergoes sulfonation at the ortho position with respect to the hydroxy group and hydrolysis of the amide group (Scheme 2).

According to the ${ }^{1} \mathrm{H}$ and ${ }^{13} \mathrm{C}$ NMR data, compound I was isolated as an inner salt containing one solvate water molecule (Scheme 3 ). The ${ }^{1} \mathrm{H}$ NMR spectrum of I contained two singlets at $\delta 7.09$ and $7.32 \mathrm{ppm}$ due to aromatic protons, a singlet at $\delta 2.15 \mathrm{ppm}$ from the methyl protons, and broadened signals at 3.8, 9.5, $11.1 \mathrm{ppm}$, which were assigned to protons in the ammonium and $\mathrm{OH}$ groups and hydration water.
Under analogous conditions, 2,5-dimethoxyphenyl methyl ketone oxime was converted into 2,5-dimethoxyaniline, but no sulfonation was observed.

Scheme 2.
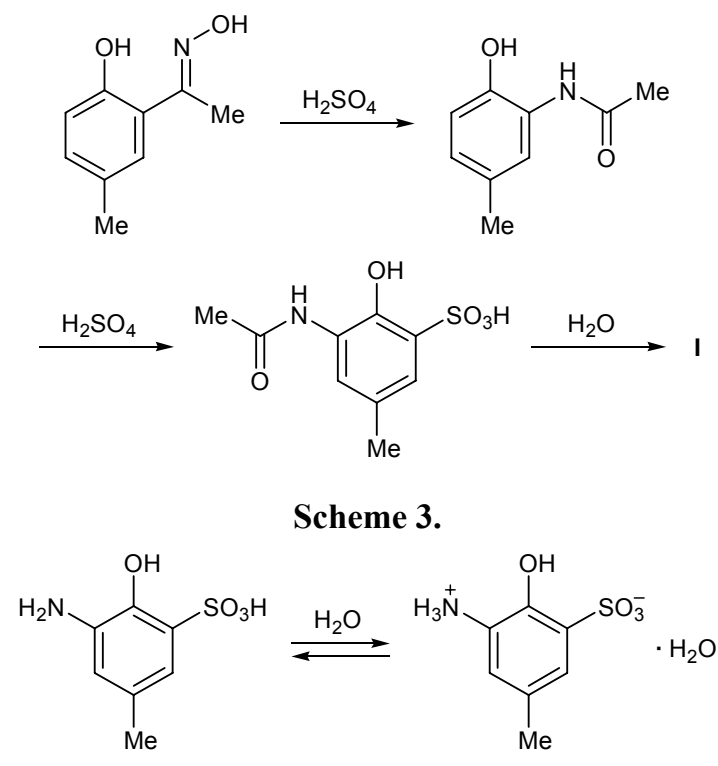

3-Amino-2-hydroxy-5-methylbenzenesulfonic acid (I). A mixture of $16.5 \mathrm{~g}(0.1 \mathrm{~mol})$ of 2-hydroxy5 -methylphenyl methyl ketone oxime in $20 \mathrm{ml}$ of aqueous acetone and $9.8 \mathrm{~g}(0.1 \mathrm{~mol})$ of $60 \%$ sulfuric acid was heated for $2 \mathrm{~h}$ under reflux. After removal of acetone, crystals separated from the aqueous phase and were filtered off, $\mathrm{mp}>300^{\circ} \mathrm{C}$ (decomp.); the product was insoluble in organic solvents and soluble in hot water. Found, \%: N 7.11; S 15.34. $\mathrm{C}_{7} \mathrm{H}_{9} \mathrm{O}_{4} \mathrm{NS}$. Calculated, \%: N 6.89; S 15.76.

The ${ }^{1} \mathrm{H}$ NMR spectra were recorded on a Bruker A-300 spectrometer at $300 \mathrm{MHz}$ using tetramethylsilane as internal reference and $\mathrm{CDCl}_{3}$ as solvent. 